\title{
IMAGING TECHNOLOGIES IN BREAST CANCER SCREENING BEYOND MAMMOGRAPHY.
}

\author{
Shamy. $\mathbf{S}^{1 *}$, Dr. J Dheeba ${ }^{2}$ \\ *l Research Scholar, Noorul Islam University, Tamil Nadu, India. \\ ${ }^{2}$ Associate Professor/CSE,Noorul Islam University, Tamil Nadu, India.
}

*Corresponding Author: -

\begin{abstract}
: -
Still there is a passionate debate in medical world about the best screening method for Breast Cancer. Early detection is an effective way to diagnose and manage breast cancer. Mammography is the most widely used screening modality, with solid evidence of benefit for women aged 40 to 74 years. Even then it has also undergone increased scrutiny for FalsePositives with additional testing which increase radiation dose, cost and anxiety. False-Negatives with false sense of security and potential delay in cancer diagnosis. To overcome these challenges, new imaging technologies for breast cancer screening have been developed, including; X-ray Mammography, Contrast Enhanced Mammography, Digital Mammography, Ultrasound, Automated Whole Breast Ultrasound (AWBU), and Magnetic Resonance Imaging (MRI) are being evaluated. The purpose of this paper is to provide an overview of different medical imaging techniques used in the diagnosis of breast cancer. We compare their effectiveness, advantages, and disadvantages for detecting early-stage breast cancer. We mainly focusing on the comparison of these technologies with mammography for the diagnosis of breast cancer. Here we recommend Digital Mammography is the best available screening method for the early detection of Breast Cancer. Even though the optimal screening will ultimately require a personalized approach. It based on the metrics of cancer risk with selective application of specific screening technologies best suited to the individual's age, risk, and breast density.
\end{abstract}

Key words: Breast Cancer, Mammography, X-ray Mammography, Contrast Enhanced Mammography, Digital Mammography, Ultrasound, Automated Whole Breast Ultrasound (AWBU), Magnetic Resonance Imaging (MRI).

\section{(c) $(\$)$}




\section{INTRODUCTION}

Breast cancer is the second-most common and leading cause of cancer death among women in world wide. It has become a major health issue in the world over the past 50 years, and its incidence has increased in recent years. The National Cancer Institute $(\mathrm{NIH})$ estimates that there will be 232,670 new female and 2,360 new male cases of breast cancer in the U.S. in 2014[1]. About 1 in 8 U.S. women (about 12\%) will develop invasive breast cancer over the course of her lifetime [2]. The chance that breast cancer will be responsible for a woman's death is about 1 in 36 (about 3\%) [3]. Breast cancer death rates generally increase with age. $95 \%$ of new cases and $97 \%$ of breast cancer deaths occur in women 40 years of age and older [4]. According to the GLOBOCAN Project 2012, In India, 144,937 women were newly detected with breast cancer 70,218 women died of breast cancer [5]. That is $144937 / 70218=2.06=$ round it off to 2 . So roughly, in India, for every 2 women newly diagnosed with breast cancer, one women is dying of it.

If cancer or abnormal breast tissue is found early, it may be easier to treat because the cancer may have begun to spread beyond the breast by the time symptoms appear. It is generally accepted that early detection of breast cancer increases the probability of cure and mammography has been shown to reduce breast cancer mortality in population-based screening programs. Mammography is the most common screening test for breast cancer. A mammogram is an x-ray of the breast. Mammograms are less likely to find breast tumors in women younger than 50 years than in older women. This may be because younger women have denser breast tissue that appears white on a mammogram. More successful breast cancer screening requires increased sensitivity and specificity. It should limit both financial cost and radiation burden. New technological development may be overcome this barriers. However, we propose that optimal patient care will ultimately require a new paradigm with adoption of patientspecific screening strategies tailored to risk assessment based on breast density, age, family history and genetic profiles.

In this article we discuss both current practices and imaging techniques that may be combined in novel ways to achieve optimal, personalized imaging strategies for detecting breast cancer. We describe the advantages and disadvantages of Xray mammography, Digital Mammography, ultrasound, MRI, Automated Whole Breast Ultrasound (AWBU) and some of the other imaging techniques. And comparison of some of the new imaging technologies with Mammography. We also compare their performances using several metrics, including radiation safety, patient's comfort, cost, time required and ability in detecting microcalcifications, which are the first sign of breast cancer.

\section{X-ray mammography}

$\mathrm{X}$-ray Mammography also known as film mammography, is the most widely used medical imaging modality for early detection of breast cancer. Which has been available since the 1960s. In X-ray mammography the breast is exposed to very low-energy x-rays in the frequency range of 30 petahertz to 30 exahertz $(3 \times 1016 \mathrm{~Hz}$ to $3 \times 1019 \mathrm{~Hz})$, which scatter throughout breast tissue while emitting photons that are absorbed onto an image that is a projection of the entire breast (3D to $2 \mathrm{D}$ ), to form a conventional latent image. These images are then archived on a recording device.

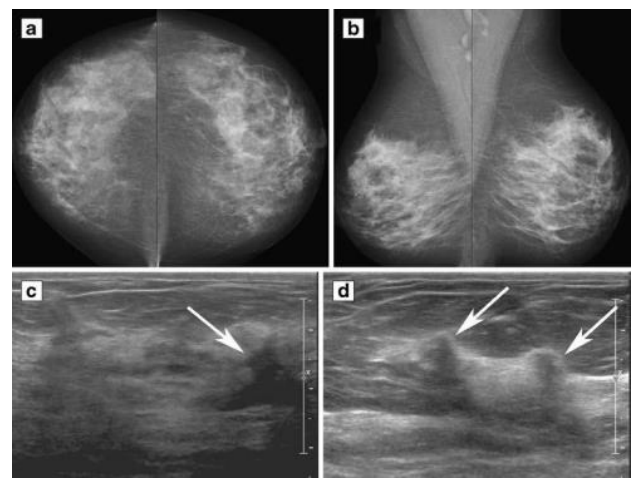

Fig.1. (a) Craniocaudal digital mammogram image of a 54 year old woman. (b) Mediolateral oblique digital mammogram image of the same patient. (c) Arrows shows a $7 \mathrm{~mm}$ grade I, stage 1, and invasive ductal carcinoma in situ on right breast. (d) Arrows shows a 10mm (d), grade I, stage 1, and invasive ductal carcinoma in situ on left breast [33].

The spatial resolution of the mammogram image is approximately 20 lines pairs $/ \mathrm{mm}$. This method can detect approximately $78 \%$ of invasive breast cancer [9] and its sensitivity is as high as $98 \%$ in women over 50 years old with fatty breasts [9]. Film mammography provides very good spatial resolution and contrast, and thus is useful for finding non palpable pathology and identifying subtle differences among the various types of soft tissue in the breast.

Film storage is one of the major concern in X- ray mammography, and if the film is damaged or inadequate, the study must be repeated. Another one major limitations of X-ray mammography is its low sensitivity in dense breasts. Mammograms of dense breast tissue common in younger women are difficult to interpret. Dense breasts are more likely to develop breast cancer and the sensitivity of mammography in these dense breasts can be low as 30\%-48\% [10]. The $\mathrm{X}$-ray ionizing radiation is another disadvantage of X-ray mammography, which may induce cancerous cells. To improve the image quality, the breast has to be compressed between the two flat surfaces. It is uncomfortable and painful for the patients. 


\section{Digital Mammography.}

In a digital mammographic system the film/screen cassette is replaced by a chemical screen along with a digital detector which detect the xray photons leaving the breast. A digital image is created when a digital detector captures photons either indirectly — using a scintillator to absorb x-rays and emit scintillated light, which is detected by photodiodes — or directly, using a photoconductor to capture $\mathrm{x}$-rays and transform them directly into a digital signal and this signal is displayed on a computer monitor. The exposure is terminated when a sufficient signal to noise ratio is achieved.

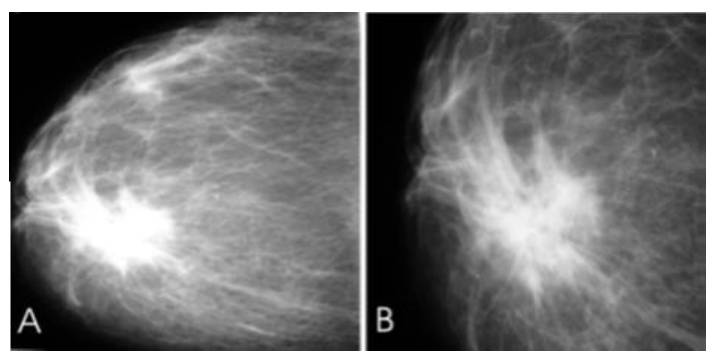

Figure 2 a,b: Mammography before surgery, craniocaudal view and magnification - left breast tumor with malignant characteristic[38]

Even if digital mammography has many potential advantages over traditional film mammography, clinical trials show that [12] the overall diagnostic accuracy levels of current digital and film mammography are similar when used in breast cancer screening. However, digital mammography may be more effective than screen-film mammography for certain women [13], [14]. For example, Spurgeon [13] showed that digital mammography depicts more tumors than screen-film mammography, especially lesions seen as microcalcifications (MCs). Pisano et al. [12] showed that digital mammography is more accurate in women under the age of 50, women with radiographically dense breasts, and premenopausal women. Digital mammography offers more advantages over film Mammography which are

- the images, which are stored electronically and the Data in Digital form

- Computer Aided detection

- can be transmitted over long distances,

- Compatibility with PACS and Telemammography, allowing clinicians in geographically remote areas to consult with distant specialists;

- Increased signal to noise ratio (SNR)

- Excellent Image Handling, the radiologist can manipulate the images to focus on 3-dimensional image of discrete areas of breast.

- Improved detection efficiency

The DMIST trial [11] (Digital Mammographic Imaging Screening Trial) compared fi lm versus digital mammography in almost 50,000 women. The trial's report in the New England Journal of Medicine concluded that "digital mammography was significantly better than conventional film mammography at detecting breast cancer in young women, premenopausal and perimenopausal women, and women with dense breasts." They added that despite the added cost $(1.5-4 \mathrm{x}$ the cost of fi $\mathrm{lm}$ mammography in the DMIST trial, which concluded in 2003), they believe "the significant improvement in accuracy in specific subgroups of women justifies the use of digital mammography in those groups." Since that trial was completed in 2003, improved understanding of the role of BRCA-1 and BRCA-2 genes in putting young women at high risk for developing breast cancer suggests that they too might benefit $t$ from digital mammography.

One of the difficulties with mammography [16] is that mammograms generally have low contrast. This makes it difficult for radiologists to interpret the results. Studies [17], [18] have shown that mammography is susceptible to a high rate of false positives as well as false negatives, causing a high proportion of women without cancer to undergo further clinical evaluation or breast biopsy, or miss the best time interval for the treatment of cancer. Several solutions have been proposed to increase the accuracy, specificity, and sensitivity of mammography and reduce unnecessary biopsies.

\section{Contrast-Enhanced Digital Mammography (CEDM)}

A recent development of mammography is contrast-enhanced digital mammography (CEDM) which uses an intravenous injection of an iodinated contrast agent in conjunction with a mammography examination [21]. . Two basic CEDM techniques are under development: temporal subtraction and dual-energy techniques. Temporal subtraction CEDM imaging produces high-energy digital mammography images and subtraction of precontrast from the postcontrast images. Dual-energy subtraction imaging exploits the energy dependence of X-ray attenuation through materials of different compositions in the breast, specifi-cally iodine and soft tissues [22]. A pair of low- and high-energy images is obtained after contrast and then the two images are combined to enhance areas of contrast uptake. This new breast imaging method can be easily implemented clinically using a current digital mammography system with minor adaptations and commercially available iodinated contrast agent. Initial clinical experience has shown the ability of CEDM to map the distribution of neovasculature induced by cancer using mammography. 
Table 1

\begin{tabular}{|l|l|l|}
\hline Accuracy of Mammography \\
\hline \multirow{2}{*}{$\begin{array}{l}\text { Stages } \\
\text { Disease }\end{array}$} & \% Detection \\
\cline { 2 - 3 } & Mammography & $\begin{array}{l}\text { Physical } \\
\text { Examination }\end{array}$ \\
\hline $\begin{array}{l}\text { Minimal } \\
\text { Carcinoma }\end{array}$ & 97 & 33 \\
\hline $\begin{array}{l}\text { Negative } \\
\text { Nodes }\end{array}$ & 92 & 51 \\
\hline Positive Nodes & 93 & 77 \\
\hline & & \\
\hline
\end{tabular}

Fig 4 Image courtesy GE

Diekmann et al [23] evaluated the diagnostic benefits of CEDM over conventional mammography. They found an increase in sensitivity from 0.43 to 0.62 on using CEDM, and also observed better sensitivity in the case of dense tissues. This is a potentially useful benefit as it is known that conventional mammography is not very sensitive in detecting cancer in dense breast tissues. . Two basic CEDM techniques are under development: temporal subtraction and dual-energy techniques. Temporal subtraction CEDM imaging produces highenergy digital mammography images and subtraction of pre-contrast from the post-contrast images. Dual-energy subtraction imaging exploits the energy dependence of X-ray attenuation through materials of different compositions in the breast, specifically iodine and soft tissues. A pair of lowand high-energy images is obtained after contrast and then the two images are combined to enhance areas of contrast uptake. This new breast imaging method can be easily implemented clinically using a current digital mammography system with minor adaptations and commercially available iodinated contrast agent. Initial clinical experience has shown the ability of CEDM to map the distribution of neo-vasculature induced by cancer using mammography.

\section{Ultrasound}

Ultrasound also known as sonography is an attractive supplement to mammography because it is widely available, , relatively inexpensive, requires no contrast injection, does not use ionizing radiation, and is well tolerated by patients. It uses sound waves to look inside a part of the body. A gel is put on the skin of the breast and a handheld instrument called a transducer is rubbed with gel and pressed against the skin. It emits sound waves and picks up the echoes as they bounce off body tissues. The echoes are converted by a computer into a black and white image on a computer screen. This test is painless and does not expose you to radiation.

Masses as cystic or solid can usually identified by ultrasound, and can recognize characteristics of solid masses that are strongly suggestive of malignancy. Sonography is particularly important in young women with breast tissue tends to be dense and thus more likely to cause a Volume-2 | Issue-5 | May, 2016 | Paper-1 falsely negative mammogram [37].Sonography takes advantage of the fact that controlled sound waves reflected off body tissues provide information not only about the distance of the tissue from the sound source, but about its size, shape, and internal consistency (e.g., fluid vs. solid). A transducer is used to transmit high-frequency sound waves into the body, and to record the character and strength of reflected waves to produce a real-time, dynamic image of the target tissue on a computer monitor. Still frames can be generated to allow the radiologist to evaluate and document the appearance of lesions and suspicious areas in the breast.

Each year, mammography is used to screen more than 44 million women in the U.S... Of those women, $36 \%$ (approximately 16 million) are referred for a second, diagnostic test. Many of these women are given a breast ultrasound exam [35]. Ultrasound waves are highfrequency sound waves that reflect at boundaries between tissues with different acoustic properties. The depth of these boundaries is proportional to the time intervals of reflection arrivals. Thus, ultrasound can map an image of tissue boundaries. Ultrasound can also provide information about blood flow by mapping the amount of acoustic frequency shift as a function of position in tissue; this is the Doppler Effect. Ultrasound holds promise as a method for detection of cancers in women with dense breast tissue, which is often problematic with conventional screen-film mammography. 


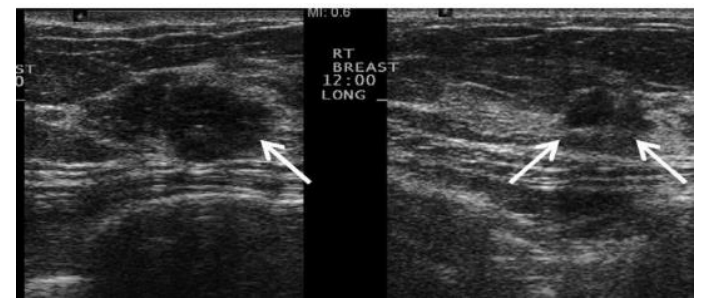

Fig 5.Longitudinal grayscale ultrasound images show two irregular hypoechoic masses (arrows), measuring $1.5 \mathrm{~cm}$ and $0.6 \mathrm{~cm}$ at the 10 - and 12- o'clock positions respectively in the right breast. Ultrasoundguided core needle biopsies revealed intermediate grade ductal carcinoma in situ at both sites [34].

Ultrasound screening is very helpful in detecting breast cancer, even though in some cases it has a higher false positive rate. Another one drawback with ultrasound imaging is, it is highly operator-dependent, requiring real-time adjustments of gain, focal zones, dynamic range, pressure, patient positioning, and, most importantly, recognition of abnormalities. Therefore, ultimately, if ultrasound imaging is to be used as a supplemental screening tool, the current model of physicianperformed scanning using hand-held transducers will likely need to be changed [36].

\section{Automated Whole-Breast Ultrasound System (AWBUS)}

AWBU is a computer-based system gathers standardized uniform image and recording ultrasound of the whole breast (AWBU: Sono- cine, Inc., 5475 Reno Corporate Dr., Suite 200, Reno, NV89511). The images were collected with multifrequency transducers within at least the 7 to $12 \mathrm{MHz}$ range. The transducer is attached to a computerguided mechanical arm, and images acquired in longitudinal rows (acquiring transverse images), overlapping 7 to $10 \mathrm{~mm}$ to ensure complete coverage. As the transducer faces in more than $95 \%$ of the examinations measured $5.2 \mathrm{~cm}$, the width of the rows without the overlap was about 4.2 to $4.5 \mathrm{~cm}$. In most women the number of rows varied from 4 to 7 for each breast. The mechanical arm controls transducer speed and position, with a trained ultrasound technologist maintaining appropriate contact pressure and orientation vertical to the skin. Approximately 150-300 images per row are immediately 3 displayed on the AWBU monitor and then permanently stored. The interval between recorded images is $0.8 \mathrm{~mm}$. typical imaging time is 10-20 min for each participant. Interpretation and reporting time for an experienced radiologist was 7-10 min per examination for typical AWBU studies.

The rate of biopsy following screening ultrasound was $5 \%$, with a positive predictive value (PPV) of $11 \%$. Furthermore, generalization of these results is limited since all study participants were at elevated risk with over half having a personal history of breast cancer (42). Studies were reported according to the American College of Radiology Breast Imaging Reporting and Data System (BI-RADS) six-point scale $(0=$ incomplete, needs additional assessment; $1=$ normal; $2=$ benign; $3=$ probably benign; 4= suspicious; 5= highly suggestive of malignancy) [40, 41].
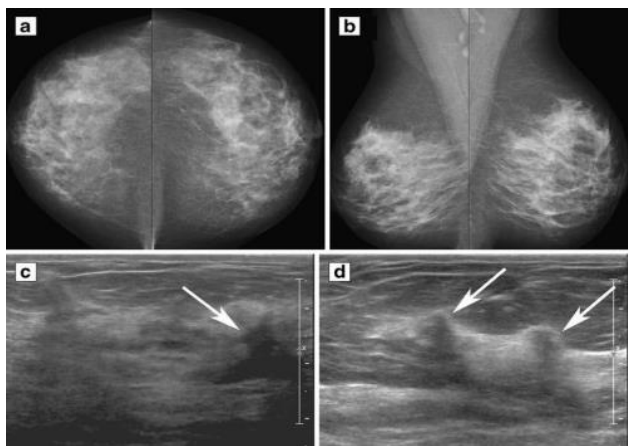

Fig 6. Selected images of a 54- year-old asymptomatic woman with dense breasts and no previous history of breast cancer. A Craniocaudal digital mammograms taken the same day as the AWBU study. b Mediolateral oblique digital mammograms taken the same day as the AWBU study. c Transverse AWBU image of the right breast at 11:30, $6 \mathrm{~cm}$ from the nipple; white arrow shows a $7 \mathrm{~mm}$, grade I, stage 1, invasive ductal carcinoma. d AWBU image of the left breast at 12:00,3 cm from the nipple; two white arrows show $10 \mathrm{~mm}$, grade I, stage 1, invasive carcinoma with lobular carcinoma in situ[39]

AWBU has several advantages over handheld ultrasound, it is more reproducible, through imaging through the entire breasts. It has higher definition with better contrast and sharpness and smaller images for review by using high resolution 2000 line reading monitor with 3D capability. It allows delayed interpretation at computer monitor base read stations with non-real time review, optimizing the radiologist. One of the limitation is, technique itself is limited, same like other ultrasound techniques, in women with large breasts. Patient cooperation is also necessary as motion beyond quiet breathing will degrade the examination. 


\section{MRI}

Magnetic resonance imaging (MRI) is valuable tool for high-risk women, when supplemental screening is planned, MRI is performed in lieu of ultrasound imaging. It is a useful tool for identifying the exact position before breast cancer surgery. Small invasive cancers and ductal carcinoma in situ can be detected using breast MRI due to remarkable advances in temporal resolution and spatial resolution [24].
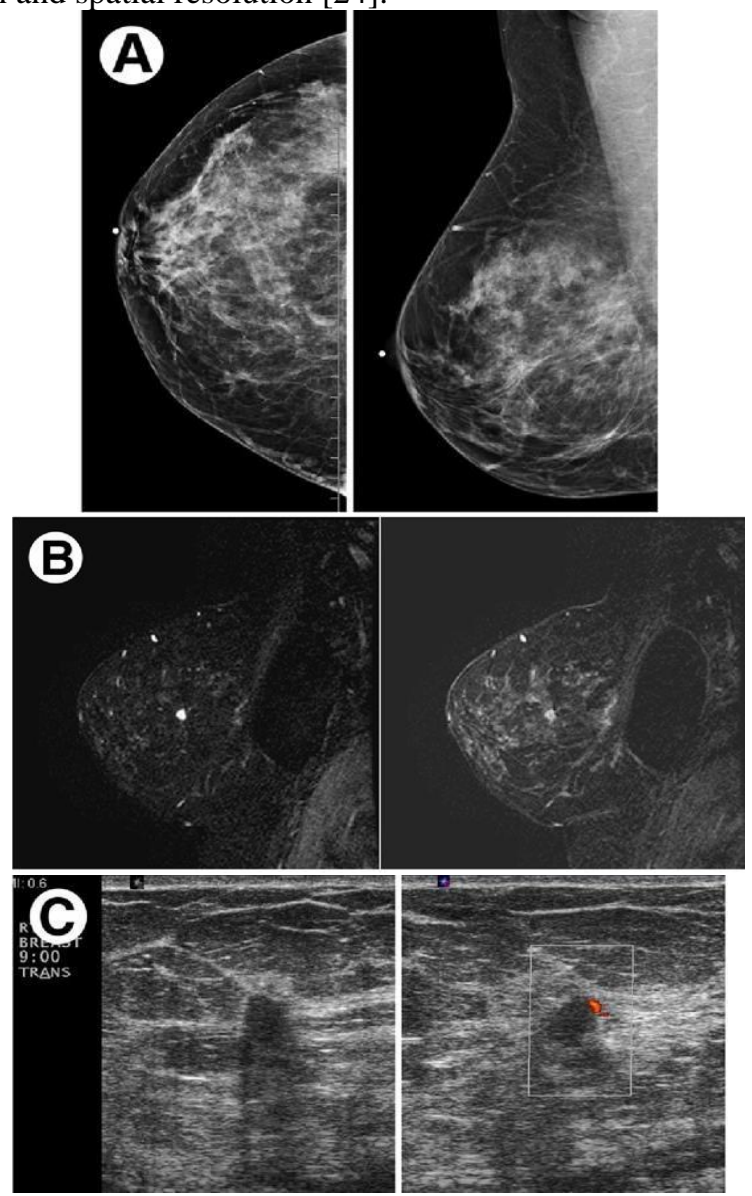

Fig.7. (A) Annual mammography screening done upon a 59-year-old woman with a strong family history of breast cancer. No suspicious mammographic findings were identified. (B) Then the patient went through MRI screening on the same day and a 8-mm suspicious mass at the 9-o'clock position was found using MRI screening. (C) Later on transverse grayscale and power Doppler ultrasound images of the right breast in the 9-o'clock region show a corresponding 7-mm irregular mass with peripheral vascularity. Then Ultrasound-guided biopsy was performed, revealing evidence of invasive ductal carcinoma [9].

MRI uses the hydrogen nucleus (single proton) for imaging purposes because this nucleus is abundant in water and fat. The magnetic property of the hydrogen nucleus is used to produce detailed images from any part of the body. The patient who is examined using MRI is placed in a magnetic field and a radio frequency wave is applied to create high contrast images of the breast. In dynamic contrast enhanced-MRI (DCE-MRI) [28], a contrast agent is injected before the images are captured. This technique has been found to be more sensitive than mammography [29]. Breast MRI is a widely used imaging modality for the early detection of breast cancer [30]. Early results suggest that MRI can dramatically improve the yield of screening certain at-risk populations. Further work may be performed to clarify the role of breast MRI in the early detection of breast cancer. Recent work on breast MRI with 3 Tesla magnets, showed that MRI ${ }^{4}$ had a higher spatial and temporal resolution and a better signal to noise ratio [31].

The American cancer society has updated its breast cancer imaging guidelines and now advocates breast MRI for certain groups of highrisk women [25]. MRI imaging uses a large magnet of 3-5 Tesla and RF coils to produce 3D images of the breast. The signals received are processed to produce the images. Compared to other imaging techniques, MRI is relatively expensive and requires an intravenous injection of gadolinium, which causes the development of nephrogenic systemic fibrosis in a small group of patients with impaired renal function [26]. Therefore, a patient with a history of renal disease may not be able to undergo breast MRI. Because this method uses large magnets it cannot be performed for breast cancer detection in patients who have pacemakers or any metal implants [27]. MRI imaging techniques are time consuming and produce blurred images. Misinterpreted MRI images require that patients undergo the same imaging process several times. Although MRI may save patients from unnecessary surgery, there is a concern that findings on MRI may prompt unnecessary excess tissue removal or in some cases unnecessary mastectomy. 
MRI can be a reliable method for biopsy or localization of breast cancer. From all the imaging techniques that have been investigated, MRI has the highest sensitivity for detecting invasive breast carcinoma and can provide valuable information that is not appreciated on the mammogram. Breast MRI screening is very encouraging when applied to high risk patients. Breast MRI is not recommended as a screening tool for women who are at average risk of developing breast cancer. Yes, breast MRI has been found to be more sensitive in detecting cancers than mammograms, which does seem like an advantage. However, a major disadvantage is that breast MRI screening results in more false positives — in other words, the test finds something that initially looks suspicious but turns out not to be cancer. If breast MRI were adopted as a screening tool for everyone, many women would end up having unnecessary biopsies and other tests. MRI is also more expensive than mammography, and dedicated breast MRI screening equipment is not widely available. [32]

Table 2 Comparisons between different imaging techniques for breast cancer detection

\begin{tabular}{|c|c|c|c|c|c|c|}
\hline $\begin{array}{l}\text { Imaging } \\
\text { Techniques }\end{array}$ & $\begin{array}{l}\text { Operating } \\
\text { Frequency Range }\end{array}$ & $\begin{array}{l}\text { Radiation } \\
\text { Safety }\end{array}$ & Effectiveness & $\begin{array}{l}\text { Patients } \\
\text { Comfort }\end{array}$ & Cost & $\begin{array}{l}\text { Time } \\
\text { required }\end{array}$ \\
\hline $\begin{array}{l}\text { X-Ray } \\
\text { mammogram }\end{array}$ & 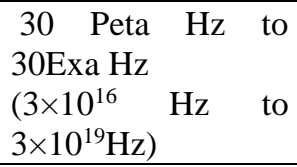 & $\begin{array}{l}\text { Ionizing } \\
\text { radiation }\end{array}$ & $\begin{array}{l}\text { Can detect tumors up } \\
\text { to few mm. Not } \\
\text { effective for dense } \\
\text { breast }\end{array}$ & Uncomfortable & Low & $\begin{array}{l}\text { Less than } \\
5 \mathrm{~min}\end{array}$ \\
\hline $\begin{array}{l}\text { Digital } \\
\text { Mammogram }\end{array}$ & $\begin{array}{l}30 \text { Peta Hz- } 30 \text { Exa } \\
\mathrm{Hz} \\
\left(3 \times 10^{16} \quad \mathrm{~Hz}\right. \\
\left.3 \times 10^{19} \mathrm{~Hz}\right)\end{array}$ & $\begin{array}{l}\text { Ionizing } \\
\text { radiation }\end{array}$ & $\begin{array}{l}\text { Can detect tumors up } \\
\text { to few mm. Not } \\
\text { effective for dense } \\
\text { breast }\end{array}$ & Uncomfortable & Low & $5-10 \min$ \\
\hline $\begin{array}{l}\text { Contrast- } \\
\text { Enhanced } \\
\text { Digital } \\
\text { Mammography } \\
\text { (CEDM) }\end{array}$ & $\begin{array}{l}30 \\
\text { Petahertz } \\
\text { to } \quad 30 \\
\text { Exahertz } \\
\left(3 \times 10^{16} \quad \mathrm{~Hz} \quad-\right. \\
\left.3 \times 10^{19} \mathrm{~Hz}\right)\end{array}$ & $\begin{array}{l}\text { Ionizing } \\
\text { radiation }\end{array}$ & $\begin{array}{l}\text { Can detect } \\
\text { tumors up } \\
\text { to few mm } \\
\text { Not effective for dense } \\
\text { breast }\end{array}$ & Uncomfortable & Low & $5-10 \mathrm{~min}$ \\
\hline Ultrasound & $\begin{array}{l}\text { 2-20 Megahertz } \\
\left(2 \times 10^{6} \mathrm{~Hz} \text { to }\right. \\
\left.20 \times 10^{6} \mathrm{~Hz}\right)\end{array}$ & $\begin{array}{l}\text { Nonionizing } \\
\text { radiation }\end{array}$ & $\begin{array}{l}\text { Can detect tumors, up } \\
\text { to few } \mathrm{cm} \text {. Effective } \\
\text { for dense breast }\end{array}$ & Comfortable & Low & $\begin{array}{c}15- \\
25 \mathrm{~min}\end{array}$ \\
\hline $\begin{array}{l}\text { Automated } \\
\text { Whole-Breast } \\
\text { Ultrasound } \\
\text { System (AWBUS) }\end{array}$ & $\begin{array}{l}\text { 2-20 Megahertz } \\
\left(2 \times 10^{6} \mathrm{~Hz} \text { to }\right. \\
\left.20 \times 10^{6} \mathrm{~Hz}\right)\end{array}$ & $\begin{array}{l}\text { Nonionizing } \\
\text { radiation }\end{array}$ & $\begin{array}{l}\text { Can detect tumors, up } \\
\text { to few } \mathrm{cm} \text {. Effective } \\
\text { for dense breast }\end{array}$ & Comfortable & Low & $\begin{array}{l}20-30 \\
\min \\
\end{array}$ \\
\hline MRI & $\begin{array}{l}\text { 1-100 Megahertz } \\
\left(1 \times 10^{6} \mathrm{~Hz}-100 \times 10^{6}\right. \\
\mathrm{Hz})\end{array}$ & $\begin{array}{l}\text { Nonionizing } \\
\text { radiation }\end{array}$ & $\begin{array}{l}\text { Effective in detecting } \\
\text { tumors up to few mm } \\
\text { Effective for dense } \\
\text { Breast }\end{array}$ & Uncomfortable & high & $\begin{array}{l}45-60 \\
\min \end{array}$ \\
\hline
\end{tabular}

\section{Conclusion}

For breast cancer screening still mammography plays the major role. Digital mammography and Contrast-Enhanced Digital Mammography (CEDM) areimportant as an enabling technology. It offers advances in image processing, transmission, and display and having the drawbacks of difficulties for screening in dense breast, radiation, and giving some Uncomfortableto the patient. To detect early stage breast cancer, the individual patient's risk profile can serve as a vital role for the entire screening process. Ultrasound and MRI are the non-ionizing breast imaging technologies. These canbe a valuable adjunctive tools inthe evaluation of lesions detected with mammography and clinical examination.AWBU has several advantages over handheld ultrasound, itis more reproducible, through imaging through the entire breasts. The women with high risk of developing breast cancer is recommended for MRI. A combination of digital mammography, automatedwhole breast ultrasound, and MRI has shown to give very good results in detecting ductal carcinoma in situ and invasive cancer. Using combinations of these techniques increases the chances of detecting breast cancer, and also reduce the rates of false positive and false negative detections. To overcome the current limitations and to increase their efficiency for screening best cancer, still need further improvements in these imaging techniques.

\section{Refferences}
[1].Breast
Cancer
Screening-National
Cancer
Institute

http://www.cancer.gov/cancertopics/pdq/screening/breast/healthprofessional.

[2].U.S. Breast Cancer Statistics - www.breastcancer.org/symptoms/understand_bc/statistics
[3].Awareness:
October
Is Breast
Cancer
Awareness
Month www.cancerresearch.purdue.edu/resources/awareness/breast-cancer-awarenessmonth.

[4]. http://www.cancer.org/acs/groups/content/@epidemiologysurveilance/documents/document/acspc-030975.pdf.

[5].GLOBOCAN 2012: Estimated Cancer Incidents, Mortality and Prevalence World Wide 2012 - International Agency for Research on Cancer: WHO 
[6].Jennifer S. Drukteinis, M.D., Blaise P. Mooney, M.D., Chris I. Flowers, MBBS, and Robert A Gatenby, M.D. -Beyond Mammography: New Frontiers in Breast Cancer Screening, Am J Med. Jun 2013; 126(6): 472-479.

[7].K. H. Ng and M. Muttarak, "Advances in mammography have improved early detection of breast cancer," J. Hong Kong College Radiol., vol. 6, no. 3, pp. 126-131, 2003.

[8].C. Lewis, "FDA sets higher standards for mammography," FDA Consum., vol. 33, no. 1, pp. 13-17, 1999.

[9].S. Carkaci, L. Santiago, B. E. Adrada, and G. J. Whitman, "Screening for breast cancer with sonography," In Seminars in Roentgenology, Vol. 46, no. 4, pp. 285, 2011.

[10]. N. F. Boyd, H. Guo, L. J. Martin, L. Sun, J. Stone, E. Fishell, R. A. Jong et al," Mammographic density and the risk and detection of breast cancer," New England Journal of Medicine, Vol. 356, no. 3, pp. 227-236, 2007.

[11]. Pisano ED, Gatsonis C, Hendrick E, et al. Diagnostic performance of digital versus fi lm mammography for breastcancer screening. N Engl J Med 2005;353:1773-1783.

[12]. E. D. Pisano, C. Gatsonis, E. Hendrick, M. Yaffe, J. Baum, S. Acharyya,E. Conant, L. Fajardo, L. Bassett, C. D’Orsi, R. Jong, and M. Rebner,"Diagnostic performance of digital versus filmmammography for breastcancerscreening," New England J. Med., vol. 353, no. 17, pp. 1773-1783, 2005.

[13]. D. Spurgeon, "Digital mammography is more accurate only for certaingroups of women, Br. Med. J, vol. 331, no.7518, pp. 653-653,2005.

[14]. M. Del, P. Mantellini, S. Ciatto, R. Bonardi, F. Martinelli, B. Lazzari, and N. Houssami, "Full-field digital versus screen-film mammography:Comparative accuracy in concurrent screening cohorts," Amer. J. Roentgenol., vol. 189, no. 4, pp. 860-866, 2007.

[15]. NCI Cancer Fact Sheets. (2007). [Online]. Available: http://www.cancer.gov/ cancertopics/factsheet/Detection/screening-mammograms.

[16]. T.Wang and N. Karayiannis, "Detection of microcalcifications in digitalmammograms using wavelets," IEEE Trans. Med. Imag., vol. 17, no. 4,pp. 498-509, Aug. 1998.

[17]. R. Bird, T. Wallace, and B. Yankaskas, "Analysis of cancers missed at screening mammography," Radiology, vol. 184, no. 3, pp. 613-617, 1992.

[18]. K. Kerlikowske, P. Carney, B. Geller, M. Mandelson, S. Taplin, K. Malvin, V. Ernster, N. Urban, G. Cutter, R. Rosenberg, and R. BallardBarbash, "Performance of screening mammography among women with and without a first-degree relative with breast cancer," Ann. Internal Med., vol. 133, no. 11, pp. 855-863, 2000.

[19]. J. Brown, S. Bryan, and R. Warren, "Mammography screening: An incremental cost effectiveness analysis of double versus single reading of mammograms," Br. Med. J., vol. 312, no. 7034, pp. 809-812, 1996.

[20]. R. Warren and S. Duffy, "Comparison of single and double reading of mammograms, and change in effectiveness with experience,” Br. J. Radiol., vol. 68, no. 813, pp. 958-962, 1995.

[21]. Dromain C, Balleyguier C, Adler G, Garbay JR, Delaloge S. Contrast-enhanced digital mammography. Eur J Radiol. 2009;69:34-42. [PubMed]

[22]. Contrast-Enhanced Digital Mammography (Chapter 2)- . Digital Mammography Medical Radiology 2010, pp 187198

[23]. Diekmann F, Freyer M, Diekmann S, Fallenberg EM, Fischer T, Bick U, Pöllinger A. Evaluation of contrastenhanced digital mammography. Eur J Radiol. 2009:Epub ahead of print.

[24]. D. L. Monticciolo, "Magnetic Resonance Imaging of the Breast for Cancer Diagnosis and Staging." Vol. 32, no. 4, pp. 319-330, 2011.

[25]. L. S. J. Sim, J. H. C. L. Hendriks, P. Bult, and S. M. C. F. Chong, "US correlation for MRI-detected breast lesions in women with familial risk of breast cancer," Clinical Radiology, Vol. 60, no. 7, pp. 801-806, 2005.

[26]. E. A. Morris, "Screening for breast cancer with MRI." Seminars in Ultrasound, CT, and MRI, Vol. 24, no. 1, pp. 4554, WB Saunders, 2003.

[27]. E. A. Morris, "Review of breast MRI: Indications and limitations," Seminars in Roentgenology, Vol. 36, no. 3, pp. 226-237, Elsevier, 2001. Heywang-Köbrunner SH, Viehweg P, Heinig A, Küchler C. Contrast-enhanced MRI of the breast: accuracy, value, controversies, solutions. Eur J Radiol. 1997;24:94-108. [PubMed]

[28]. Liu PF, Debatin JF, Caduff RF, Kacl G, Garzoli E, Krestin GP. Improved diagnostic accuracy in dynamic contrast enhanced MRI of the breast by combined quantitative and qualitative analysis. Br J Radiol. 1998;71:501-509. [PubMed]

[29]. Schnall MD. Application of magnetic resonance imaging to early detection of breast cancer. Breast Cancer Res. 2001;3:17-21. [PMC free article] [PubMed]

[30]. Lehman CD, Schnall MD. Imaging in breast cancer: Magnetic resonance imaging. Breast Cancer Res. 2005;7:215219. [PMC free article] [PubMed] 32. http://www.breastcancer.org/symptoms/testing/types/mri/screening

[31]. 33 K. M. Kelly, J. Dean, W. S. Comulada, and S.J. Lee, "Breast cancer detection using automated whole breast ultrasound and mammography in radiographically dense breasts," European Radiology, Vol. 20, no.3, pp. 734-742, 2010.

[32]. S. Carkaci, L. Santiago, B. E. Adrada, and G. J. Whitman, "Screening for breast cancer with sonography," Vol. 46, no. 4, pp. 285, 2011.

[33]. Emerging Technologies in Breast Cancer Detection By Andrew P. Smith, PhD, Patricia A. Hall, Donna M. Marcello, RT (R) (M)

[34]. W. Yang, and P. J. Dempsey, "Diagnostic breast ultrasound: current status and future directions," Radiologic Clinics of North America, Vol. 45, no. 5, pp. 845-861, 2005.

[35]. RadiologyInfo. Ultrasound of the Breast. www.radiologyinfo.org/ 
[36]. The Role of Imaging Techniques in Diagnosis of Breast Cancer - Current Health Sciences Journal Vol. 37, No. 2, 2011

[37]. Kevin M. Kelly,Judy Dean, W. Scott Comulada, Sung-Jae Lee - Breast cancer detection using automated whole breast ultrasound and mammography in radiographically dense breasts - Eur Radiol (2010) 20: 734-742 DOI 10.1007/s00330-009-1588-y

[38]. D’Orsi CJ, Bassett LW, Berg WA et al (2003) Breast Imaging Reporting and Data system, BI-RADS: mammography, 4th edn. American College of Radiology, Reston, VA

[39]. Mendelson EB, Baum JK, Berg WA, Merritt CRB, Rubin E (2003) Breast Imaging Reporting and Data System, BIRADS: Ultrasound, 1st edn. American College of Radiology, Reston, VA

[40]. Berg WA, Zhang Z, Lehrer D, et al. Detection of breast cancer with addition of annual screening ultrasound or a single screening MRI to mammography in women with elevated breast cancer risk. JAMA: the journal of the American Medical Association. 2012;307(13):1394-404. [PMC free article] [PubMed]

[41]. A Survey of Medical Imaging Techniques Used for Breast Cancer Detection-Islam, M.S. ; Dept. of Electr. Eng., Univ. of North Dakota, Grand Forks, ND, USA ; Kaabouch, N. ; Wen Chen Hu- IEEE Conference Publications.

[42]. Beyond Mammography: New Frontiers in Breast Cancer Screening -Jennifer S. Drukteinis, M.D., Blaise P. Mooney, M.D., Chris I. Flowers, MBBS, and Robert A Gatenby, M.D

[43]. Breast imaging: A survey- World J Clin Oncol. 2011 Apr 10; 2(4): 171-178. Published online 2011 Apr 10. doi: 10.5306/wjco.v2.i4.171 PMCID: PMC3100484

[44]. Emerging Technologies in Breast Cancer Detection- By Andrew P. Smith, PhD, Patricia A. Hall, Donna M. Marcello, $R T(R)(M)$

[45]. Recent Advances in Breast-Specific Imaging -Claudia G. Berman, MD

[46]. The Role of Imaging Techniques in Diagnosis of Breast Cancer - Current Health Sciences Journal Vol. 37, No. 2 , 2011 